\title{
VITAMIN D2 LEVELS IN TYPE-2 DIABETES MELLITUS PATIENTS IN ANDAMAN AND NICOBAR ISLANDS
}

\section{Manasa Mekkadath Vijayan ${ }^{1}$, Shivakrishna Gouroju *2.}

${ }^{1}$ Resident medical officer, Department of General medicine, Amrita Health center, Port Blair, Andaman, India.

${ }^{* 2}$ Tutor in Department of Biochemistry, Andaman and Nicobar Island Institute of Medical sciences, Port Blair, Andaman, India.

\section{ABSTRACT}

Background and Objective: Vitamin D deficiency has been recently linked to diabetes, biochemical tests are restricted to traditional monitoring of glucose. Therefore, introducing vitamin D test in Andaman and Nicobar Islands hospitals may help in the management of the disease.

Materials and methods: This case-control study comprised 30 type 2 diabetic patients (19 males and 11 females) and 30 healthy controls ( 18 males and 12 females) were included in the study. Serum vitamin D2, serum glucose, Glycated hemoglobin ( $\mathrm{HbA} 1 \mathrm{c}$ ) was measured. Data were computer analyzed using Excl spared sheet and SPSS version 18.0 .

Results: The mean ages of cases and controls were $39.9 \pm 6.84$ and $37.7 \pm 9.95$ years, $p=0.32$ respectively. The levels of blood $\mathrm{HbA1c}$, Fasting blood glucose and Post Prandial Blood Glucose levels were significantly increased in cases compared to controls $(9.04 \pm 1.34$ vs. $5.95 \pm 0.14 \%, P=0.00 ; 178.27 \pm 32.13$ vs. $91.67 \pm 13.61 \mathrm{mg} / \mathrm{dl}, \mathrm{P}=0.00$; and $287.03 \pm 42.66$ vs $124.23 \pm 8.01 \mathrm{mg} / \mathrm{dl}, \mathrm{p}=0.00$ respectively). Vitamin $\mathrm{D} 2$ level were cases $9.71- \pm 1.82 \mathrm{ng} / \mathrm{ml}$, and controls $34.47 \pm 3.06 \mathrm{ng} / \mathrm{ml}$ were also statistically significantly decreased $(p=0.00)$ in type -2 diabetic patients when compared with healthy controls. Vitamin D2 levels were negatively correlating with age, FBS, PPBS, and HbA1c $(r=-0.284, p=0.128 ; r=-0.064, p=0.738 ; r=-0.059, p=0.757 ;$ and $r=-0.077, p=0.685$ respectively) in cases.

Conclusions: Serum vitamin D2 was significantly lower in type 2 diabetic patients compared to controls in Andaman and Nicobar Islands. Serum vitamin D2 was negatively correlated with Age, FBS, PPBS, and HbA1c. It's accepted that vitamin D treatment improves insulin resistance. Therefore, supplementation of vitamin $D$ to type 2 diabetic patients in the Andaman and Nicobar Islands hospitals and clinics may be useful in the disease management.

KEY WORDS: Type 2 diabetic patients, HbA1c, Serum vitamin D2, Andaman and Nicobar Islands.

Address for correspondence: Dr. Shivakrishna Gouroju, Tutor in Department of Biochemistry, Andaman and Nicobar Island Institute of Medical sciences, Port Blair, Andaman.

E-Mail: skgouroju@gmail.com

\begin{tabular}{|c|c|c|}
\hline \multicolumn{3}{|c|}{ Online Access and Article Informtaion } \\
\hline \multirow{2}{*}{ Quick Response code } & \multicolumn{2}{|c|}{$\begin{array}{l}\text { International Journal of Integrative Medical Sciences } \\
\qquad \text { www.imedsciences.com }\end{array}$} \\
\hline & $\begin{array}{l}\text { Received: 11-04-2018 } \\
\text { Reviewed: 11-04-2018 }\end{array}$ & $\begin{array}{l}\text { Accepted: } 22-04-2018 \\
\text { Published: } 30-04-2018\end{array}$ \\
\hline Source of Funding: Self & \multicolumn{2}{|c|}{ Conflicts of interest: None } \\
\hline
\end{tabular}

\section{BACKGROUND}

The more prevalent form, type 2 diabetes, accounts for more than $90 \%$ of cases [1]. Type 2 diabetes usually begins as insulin resistance, a disorder in which the cells do not use insulin properly. As the need for insulin rises, the pancreas gradually loses its ability to produce it [2]. Lack of insulin action and/or secretion in type 2 diabetes induces hepatic glucose output by inhibiting glycogen synthesis and stimulating glycogenolysis and gluconeogenesis then 
increased rates of hepatic glucose production result in development of overt hyperglycemia, especially fasting hyperglycemia [3-5]. In such conditions, lipolysis in adipose tissue is promoted leading to elevated circulating levels of free fatty acids. In addition, excess fatty acids in serum of diabetics are converted into phospholipids and cholesterol in liver. These two substances along with excess triglycerides formed at the same time in liver may be discharged into blood in the form of lipoproteins [6]. In addition, disturbance in liver and kidney functions was also reported in type 2 diabetes [7-9].

Fat soluble vitamin-D is plays an essential role in calcium homeostasis and the maintenance of normal function in multiple tissues. Vitamin-D either directly from the diet or through exposure to solar ultraviolet $B$ radiation obtains $[10,11]$. In addition to its well-recognized effects on skeletal health, vitamin $D$ has suggested to have a potential role in other disease states and health conditions including cardiovascular disease, type 2 diabetes, autoimmune disorders and cancer [12-16].

Numerous studies have found that patients with type 2 diabetes or impaired glucose tolerance are significantly more likely to have a lower serum vitamin $D$ concentration compared to those without diabetes $[17,18]$. In addition, recent studies reported a significant inverse association of serum vitamin $D$ with insulin resistance $[19,20]$ as well as a positive association between vitamin $D$ and $\beta$-cell function $[21,23]$. However, no previous study linked vitamin $D$ to diabetes mellitus in Andaman. Therefore, the present study is the first to assess serum vitamin $D$ level in type 2 diabetic patients from Andaman and Nicobar Islands.

\section{MATERIALS AND METHODS}

This case control study was conducted at General Medicine department with collaboration with Biochemistry department. We included A total of 60 (30 type-2 diabetic patients, and 30 healthy controls) age and sex matched subjects were participated in the study by giving informed consent form from Amrita Health center, Port Blair. Patients with chronic renal failure, glomerular nephritis, arthritis, bone disorders, pregnant women, and vitamin-D supplementing patients, Patients who take hormone replacement therapy or corticosteroid therapy were excluded from the study.

\section{Limitation of the study}

1. Sample collection was relatively difficult as many patients refuse to participate in the study.

2. The number of patients who frequently visiting the diabetic clinics was relatively low.

Sample collection and analysis: After an overnight fast of 12 to $14 \mathrm{hrs}, 5 \mathrm{ml}$ blood was collected by veni puncture. $3 \mathrm{ml}$ of blood was collected in anticoagulant (EDTA and fluoride) vacutainer. The remaining $2 \mathrm{ml}$ is taken into another bottle and allowed to clot. Serum and plasma were separated. The blood sugar by GOD-POD method and Glycated Hemoglobin by Micro column method on RA-50 instrument, and Serum Vitamin D2 estimated by enzyme linked immunoassay (ELISA) is designed by Calbiotech, Inc for the quantitation of total 25-OH Vitamin $D$ in human serum and plasma were estimated on the same day on.

Statistical analysis: All values obtained will be expressed as Mean ( \pm SEM). Unpaired two-tailed student $t$-test will be performed to compare the difference in the means between controls and study group. A ' $P$ ' value $<0.05$ will be considered as statistically significant. Statistical Analysis will be done by using Microsoft excel spread sheets. SPSS program version 18.0 was also used for correlation.

\section{RESULTS}

A total number of 60 subjects, 30 healthy controls (Males: 18, \& Females: 12) and 30 cases (type-2 Diabetic subjects: Males: 19, and Females: 11) were include in the study.

Graph 1: Shows age distribution in cases and controls.

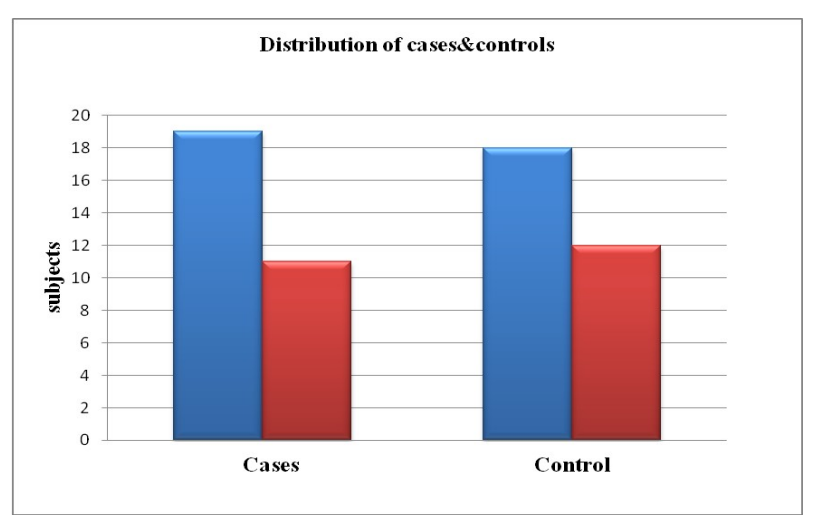


Table 1: Shows compression between cases and controls.

\begin{tabular}{|c|c|c|c|c|c|}
\hline & \multicolumn{2}{|c|}{ Cases } & \multicolumn{2}{c|}{ Controls } & \\
\cline { 2 - 6 } & Mean & SD & Mean & SD & p-value \\
\hline Age & 39.9 & 6.84 & 37.7 & 9.95 & 0.32 \\
\hline FBS & 216.43 & 26.6 & 91.67 & 13.61 & $0.00^{*}$ \\
\hline PPBS & 317.4 & 66.69 & 124.23 & 8.01 & $0.00^{*}$ \\
\hline HbA1C & 9.47 & 1.03 & 5.95 & 0.14 & $0.00^{*}$ \\
\hline Vitamin-D2 & 9.71 & 1.82 & 34.47 & 3.06 & $0.00^{*}$ \\
\hline
\end{tabular}

$*<0.005$ is Statistically Significant

Table 2: shows Vitamin D2 and HbA1c correlation with age, FBS, PPBS, HbA1c and Vitamin-D2 in cases.

\begin{tabular}{|c|c|c|c|c|c|c|}
\hline \multicolumn{2}{|c|}{} & Age & FBS & PPBS & HbA1c & VitD2 \\
\hline \multirow{2}{*}{ Age } & $\mathbf{r}$ & & -0.055 & -0.064 & 0.096 & -0.284 \\
\cline { 2 - 7 } & $\mathbf{p}$ & & 0.773 & 0.735 & 0.613 & 0.128 \\
\hline \multirow{2}{*}{ FBS } & $\mathbf{r}$ & -0.055 & & $0.677^{* *}$ & $0.742^{* *}$ & -0.064 \\
\cline { 2 - 7 } & $\mathbf{p}$ & 0.773 & & 0 & 0 & 0.738 \\
\hline \multirow{2}{*}{ PPBS } & $\mathbf{r}$ & -0.064 & $.677^{* *}$ & & $.726^{* *}$ & -0.059 \\
\cline { 2 - 7 } & $\mathbf{p}$ & 0.735 & 0 & & 0 & 0.757 \\
\hline \multirow{2}{*}{ HbA1c } & $\mathbf{r}$ & 0.096 & $0.742^{* *}$ & $0.726^{* *}$ & & -0.077 \\
\cline { 2 - 7 } & $\mathbf{p}$ & 0.613 & 0 & 0 & & 0.685 \\
\hline \multirow{2}{*}{ VitD2 } & $\mathbf{r}$ & -0.284 & -0.064 & -0.059 & -0.077 & \\
\cline { 2 - 7 } & $\mathbf{p}$ & 0.128 & 0.738 & 0.757 & 0.685 & \\
\hline
\end{tabular}

Graph 2: Shows the Vitamin- D2 levels in both cases and controls.

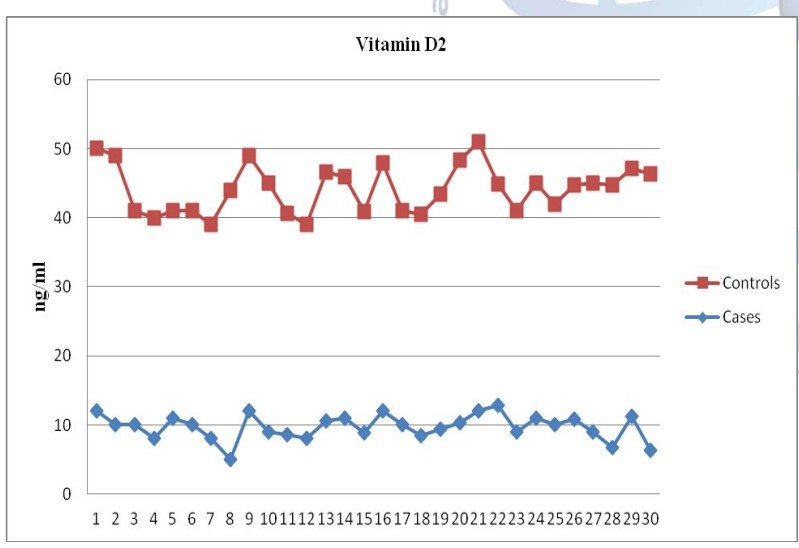

\section{DISCUSSION}

Diabetes mellitus is a metabolic disorder characterized by impairment of carbohydrate, lipid and protein metabolism. Its global prevalence rate is alarming. The total number of people with diabetes worldwide is projected to rise from 108 million in 1980 to 422 million in 2014 [24]. The global prevalence of diabetes among adults over 18 years of age has risen from $4.7 \%$ in 1980 to $8.5 \%$ in 2014 [24]. This has been rising more rapidly in middle- and low-income countries, its major cause of blindness, kidney failure, heart attacks, stroke and lower limb amputation. In 2015, an estimated 1.6 million deaths were directly caused by diabetes. WHO projects that diabetes will be the seventh leading cause of death in 2030 [24] making it one of the most important public health challenges. Despite that, there are under-diagnosis and under-reporting of the disease in the Andaman and Nicobar Islands. Type 2 diabetes (non-insulin-dependent, or adult-onset) results from the body's ineffective use of insulin. Type 2 diabetes comprises the majority of people with diabetes around the world, and is largely the result of excess body weight and physical inactivity. Symptoms may be similar to those of type 1 diabetes, but are often less marked. As a result, the disease may be diagnosed several years after onset, once complications have already arisen. Until recently, this type of diabetes was seen only in adults but it is now also occurring increasingly frequently in children. Healthy diet, regular physical activity, maintaining a normal body weight and avoiding tobacco use are ways to prevent or delay the onset of type 2-diabetes. Diabetes can be treated and its consequences avoided or delayed with diet, physical activity, medication and regular screening and treatment for complications.

In the present study, A total number of 60 subjects, 30 healthy controls (Males: 18, \& Females: 12 ) and 30 cases (type-2 Diabetic subjects: Males: 19, and Females: 11$)$ were include in the study and the mean age group of cases vs controls $39.9 \pm 6.84$ vs $37.7 \pm 9.95$ respectively and there is no statistically significance was found ( $p=0.32)$. FBS, PPBS, $\mathrm{HbA1C}$, and Vitamin D2 levels were studied in both groups. The mean and SD of fasting blood sugar level were cases $216.43- \pm 26.6 \mathrm{mg} / \mathrm{dl}$, controls $91.67 \pm 13.61 \mathrm{mg} / \mathrm{dl}$, post prandial blood sugar level were cases $317.40- \pm 66.69 \mathrm{mg} / \mathrm{dl}$, controls $124.23 \pm 8.01 \mathrm{mg} / \mathrm{dl}$, and Glycated haemoglobin level in cases $9.470 \pm 1.03 \%$ and in the controls $5.95 \pm 0.14 \%$ were also statistically significantly increased $(p=0.00,0.00$, and 0.00 respectively) in type -2 diabetic patients when compared with healthy controls. In type-2 diabetes cases the HbA1c was significantly positively correlating with the FBS and PPBS.

As indicated in the present study, the mean blood $\mathrm{HbA} 1 \mathrm{c}$ and serum glucose level were significantly higher in cases compared to controls. Similar results were obtained [8, 25-28]. 
In diabetes, prolonged hyperglycemia super drives nonenzymatic protein glycation, which forms reversible Schiff bases and Amadori compounds. A series of further complex molecular rearrangements then yield irreversible advanced glycosylated end-products (AGEs). AGEs accumulate in the circulating blood and in various tissues $[29,8]$. It is reported that the levels of $\mathrm{HbA} 1 \mathrm{c}$ in the blood reflect the glucose levels to which the erythrocyte has been exposed during its lifespan [30]. Therefore, the $\mathrm{HbA} 1 \mathrm{c}$ test is attractive as it measures chronic glycaemia, rather than instantaneous blood glucose levels. HbA1c has been used as an objective marker of average glycaemic control for many years, has an accepted place in the monitoring of patients with diabetes, and is relied on for significant management decisions, such as initiation of insulin therapy [31].

Vitamin $D$ is a multifunctional hormone that can affect many essential biological functions, ranging from immune regulation to mineral ion metabolism. Although the major function of vitamin $D$ is to maintain calcium and phosphate homeostasis and to promote bone mineralization, many extra skeletal roles for vitamin $D$ have been identified [32]. Recently found that vitamin $D$ inadequacy is associated with significant coronary artery stenosis in a community-based elderly cohort [33]. Other investigators have shown that low vitamin D status is associated with an increased risk of various diseases, such as cancer, hypertension, and cardiovascular disease [32].

In the present study vitamin D2 level were cases $9.71- \pm 1.82 \mathrm{ng} / \mathrm{ml}$, and controls $34.47 \pm 3.06 \mathrm{ng} /$ $\mathrm{ml}$ were also statistically significantly decreased $(p=0.00)$ in type -2 diabetic patients when compared with healthy controls. Vitamin D2 levels were negatively correlating with age, FBS, PPBS, and HbA1c $(r=-0.284, p=0.128 ; r=-$ $0.064, p=0.738 ; r=-0.059, p=0.757$; and $r=-0.077$, $p=0.685$ respectively). The present results revealed that the number of cases having vitamin $D$ deficiency and insufficiency were significantly higher than that of controls. Vitamin D deficiency and insufficiency were found to be prevalent among type 2 diabetic patients [34-36].

When compared with controls, cases showed significant decrease in the mean level of serum vitamin D. This means that deficiency in vitamin D levels are linked to type 2 diabetes. Such finding is in agreement with that demonstrated by Subramanian et al., [34] and Yu et al., [37]. In addition, Nikooyeh et al., [38]; Afsaneh et al., [20] and Nasri et al., [39] concluded that supplementation of vitamin $D$ is associated with a lower risk of type 2 diabetes.

The role of vitamin $D$ in the pathophysiology of type 2 diabetes is a subject of debate in the scientific community. Some mechanisms are proposed to explain how vitamin $D$ deficiency promotes type 2 diabetes. The vitamin $D$ receptors (VDRs) are widely expressed in adipose, pancreatic, and possibly muscle cells [40].

In the $\beta$-pancreatic cells, vitamin D appears to modulate directly insulin synthesis via the nuclear VDR, since there are VDR elements in the insulin promoter genes [41]. Vitamin D may also promote morphological improvement in pancreatic islet cells, decrease apoptosis, and have nongenomic effects mediated by messenger VDR [42]. Vitamin D can also act indirectly on the control of diabetes by acting on osteoblast to activate the synthesis of osteocalcin 6OAffoldS! Orhe high increase in osteocalcin synthesis appears to improve glucose tolerance by stimulating insulin synthesis in the pancreas [43]. It's accepted that vitamin D treatment improves insulin resistance [20].

Similar to the present study in other Asian countries, which indicated that up to $70 \%$ of the general population had vitamin $D$ insufficiency, defined as $30 \mathrm{ng} / \mathrm{mL}$ 25(OH)D [14]. This may represent a public health problem, considering the numerous complications and diseases associated with vitamin D deficiency [45].

Biochemical tests of the disease are restricted to monitoring blood glucose level when the patient visits the clinic. This necessitated further assessment of other biochemical features in blood such as vitamin D, its deficiency was recently linked to type-2 diabetes $[46,36]$. Therefore, supplementation of vitamin D to type 2 diabetic patients in the Andaman and Nicobar Islands hospitals and clinics may be useful in the disease management. The present study isthe first to assess serum vitamin $D$ level in type 2 diabetic patients from Andaman and Nicobar Islands. 


\section{CONCLUSION}

The levels of Fasting blood glucose, Post Prandial Blood Glucose, and blood HbA1c levels were significantly increased in type -2 diabetic cases compared to healthy controls, and the $\mathrm{HbA} 1 \mathrm{c}$ is significantly positively correlating with FBS, PPBS. Vitamin D2 levels were statistically significantly decreased in type -2 diabetic patients when compared with healthy controls. Vitamin D2 levels were negatively correlating with age, FBS, PPBS, and HbA1c in cases. Vitamin $D$ may also promote morphological improvement in pancreatic islet cells, decrease apoptosis, and have nongenomic effects mediated by messenger VDR. Vitamin $D$ can also act indirectly on the control of diabetes by acting on osteoblast to activate the synthesis of osteocalcin hormone. The high increase in osteocalcin synthesis appears to improve glucose tolerance by stimulating insulin synthesis in the pancreas. It's accepted that vitamin D treatment improves insulin resistance. Therefore, supplementation of vitamin D to type 2 diabetic patients in the Andaman and Nicobar Islands hospitals and clinics may be useful in the disease management.

\section{REFERENCES}

[1]. Olefsky, J.M. Prospects for Research in diabetes mellitus. The Journal of American Medical Association. 2001;285(5): 628-32.

[2]. Cohen $P$. The 20th century struggle to decipher insulin signaling. Nature Reviews, Molecular Cell Biology. 2006;7(12): 867-73.

[3]. Michael. R., Kulkarni C., Postic S., Previs G, Shulman M., Magnuson C., et al. Loss of insulin signaling in hepatocytes leads to severe insulin resistance and progressive hepatic dysfunction. Molecular Cell. 2000;6(1):87-97.

[4]. Guyton A.C. and Hall J.E. 2006: Textbook of Medical Physiology. 11th ed, Philadelphia, Pennsylvania: Saunders/Elsevier.

[5]. Holt R.I.G. and Hanley N.A. 2012: Essential Endocrinology and Diabetes. 6th ed, Chichester, West Sussex, Wiley-Blackwell.

[6]. Jaworski K., Sarkadi-Nagy E., Duncan R.E. Regulation of triglyceride metabolism. IV. Hormonal regulation of lipolysis in adipose tissue. American Journal of Physiology, Gastrointestinal and Liver Physiology. 2007;293(1):1-4.

[7]. Sharma A., Hirulkar N.B., Wadel P., Das P. Influence of Hyperglycemia on Renal Function Parameters in Patients with Diabetes Mellitus. International Journal of Pharmaceutical \& Biological Archives. 2011;2(2):734-9.
[8]. Yassin M., Altibi H., El Shanti A. Clinical and biochemical features of type 2 diabetic patients in Gaza Governorate, Gaza Strip. West African Journal Medicine. 2011;30(1): 51-6.

[9]. Atiba A.S., Oparinde D.P., Babatunde O.A., NiranAtiba T.A., Jimoh A.K., Adepeju, A.A. Liver Enzymes and Lipid Profile Among Type 2 Diabetic Patients in Osogbo, Nigeria. Greener Journal of Medical Sciences. 2013;3(5): 174-8.

[10]. Holick M.F. Vitamin D: evolutionary, physiological and health perspectives. Curr Drug Targets. 2011;12(1):4-18.

[11].Kannan Swati and Lim W. Henry (2014): Photoprotection and vitamin D: a review. Photodermatol Photoimmunol Photomed. John Wiley \& Sons A/S. Published by John Wiley \& Sons Ltd.

[12]. Reese R.W. Vitamin D and bone health. Journal of Lancaster General Hospital. 2006;(1):78-87.

[13]. Drake M.T., Maurer M.J., Link B.K., Habermann T.M., Ansell S.M., Micallef I.N., et al. Vitamin D insufficiency and prognosis in non-Hodgkin's lymphoma. Journal Clinical Oncology. 2010; (28):4191-8.

[14]. Dalgard C, Petersen MS, Weihe P., Grandjean P. Vitamin D Status in Relation to Glucose Metabolism and Type 2 Diabetes in Septuagenarians. Journal of Diabetes Care. 2011;6:1284-8.

[15]. Joergensen C., Reinhard H., Schmedes A., Hansen P.R., Wiinberg N., Petersen C.L., et al. Vitamin D levels and asymptomatic coronary artery disease in type 2 diabetic patients with elevated urinary albumin excretion rate. Journal of Diabetes Care. 2012;(35):168-72.

[16]. Grober U., Spitz J., Reichrath J., Kisters K., Holick M.F. Vitamin D: Update 2013 from rickets prophylaxis to general preventive healthcare. Dermato-Endocrinology. 2013;5:3, e2-331-e2-347.

[17]. Targher G, Bertolini L, Padovani R, Zenari L, Scala L, Cigolini M. Serum 25-Hydroxyvitamin D Concentrations and Carotid Artery Intima-media thickness Among Type 2 Diabetic Patients. Journal of Clinical Endocrinology. 2006; (5):593-7.

[18]. Gorham E. D., Garland C.F., Burgi A. A., Mohr S. B., Zeng K., Hofflich $\mathrm{H}$., et al. Lower prediagnostic serum 25-hydroxyvitamin $\mathrm{D}$ concentrationis associated with higher risk of insulin-requiring diabetes: a nestedcase-control study. Journal of Diabetologia. 2012; (55):3224-7.

[19]. Tracy S. Moreira and Mazen J. Hamadeh. The role of vitamin $D$ deficiency in the pathogenesis of type 2 diabetes mellitus. European Journal of Clinical Nutrition and Metabolism. 2010;(5): 155-65.

[20]. Afsaneh Talaei, Mohnaz Mohamadi and Zahra Adgi. The effect of Vitamin D on Resistance in Patients with Type 2 Diabetes. Journal of Diabetology and Metabolic Syndrome. 2013;5:8.

[21]. Palomer X., Gonza'lez-Clemente J.M., Blanco-Vaca F., D. Mauricio. Role of vitamin $D$ in the pathogenesis of type 2 diabetes mellitus . Journal of Diabetes, Obesity and Metabolism. 2008;(10):185-97. 
[22]. Ozfirat Zehra and Chowdhury A Tahseen. Vitamin D deficiency and type 2 diabetes. Postgrad Medicine. 2010; (86): 18-25.

[23]. Takiishi T., Gysemans C., Bouillon R., Mathieu C. Vitamin D and diabetes. Rheum Dis Clinical North American. 2012;38(1):179-206.

[24]. Projections of global mortality and burden of disease from 2002 to 2030. Mathers CD, Loncar D. PLoS Med. 2006;3(11):e442.

[25]. Qi. X., Li L., Yang G., Liu J., Li K., Tang Y., et al. Circulating obestatin levels in normal subjects and in patients with impaired glucose regulation and type 2 diabetes mellitus. Clinical Endocrinology. 2007;66(4): 593-7.

[26]. Nicholas J., Charlton J., Dregan A., Gulliford M.C. Recent HbA1c Values and Mortality Risk in Type 2 Diabetes. Population-Based Case-Control PLoS One. 2013;8(7): e68008.

[27].Ozougwu J., C. Obimba K., C. Belonwu C. D., Unakalamba C. B. The pathogenesis and pathophysiology of type 1 and type 2 diabetes mellitus. Journal of Physiology and Pathophysiology. 2013; 4(4):46-57.

[28]. Shubrook H Jay. Insulin for type 2 diabetes: How and when to get started. The Journal of Family Practice. 2014; 63: 2.

[29]. Furth A.J. Glycated proteins in diabetes. British Journal of Biomedical Sciences. 1997;54(3): 192-200.

[30]. Goldstein D.E., Little R.R., Lorenz RA., Malone J.I., Nathan, D., Peterson C.M. Tests of glycemia in diabetes. Diabetes Care. 2004;27(1): 1761-1763.

[31]. d'Emden M.C., Shaw J.E., Colman P.G., Colagiuri S., Twigg S.M., Jones G., et. Al. The role of HbA1c in the diagnosis of diabetes mellitus in Australia. Medical Journal of Australia. 2012;197(4): 220-1.

[32]. Rosen CJ, Adams JS, Bikle DD, Black DM, Demay $M B$, Manson JE, et al. The nonskeletal effects of vitamin d: an endocrine society scientific statement. Endocr Rev 2012;33:456-92.

[33].Lim S, Shin H, Kim MJ, Ahn HY, Kang SM, Yoon JW. et al. Vitamin $D$ inadequacy is associated with significant coronary artery stenosis in a communitybased elderly cohort: the Korean Longitudinal Study on Health and Aging. J Clin Endocrinol Metab 2012;97:169-78.

[34]. Subramanian Anita, Nigam Priyanka, Misra Anoop, Pandey Mohan Ravinder, Mathur Meeta, et al. Severe vitamin $D$ deficiency in patients with Type 2 diabetes in north India. Diabetes Manage. 2011;1(5): 477-83.

[35]. Taheri Ehsaneh, Saedisomeolia Ahmad, Djalali Mahmoud, Qorbani Mostafa, Civi Madani Manouchehr. The relationship between serum 25hydroxy vitamin D concentration and obesity in type 2 diabetic patients and healthy subjects. Journal of Diabetes \& Metabolic Disorders. 2012;11:16.
[36]. Djalali M, Taheri E, Saedisomeolia A, Djazayeri A, Rahemi A, Hashemi M et. al.. Vitamin D Status of Type 2 Diabetic Patients Compared with Healthy Subjects in the Islamic Republic of Iran. Journal of Eastern Mediterranean Health. 2013;(9)1-6.

[37]. Yu Re Jung, Lee Ah Sang, Lee Jae-Geun, Seong Myeong Gil, Ko Joo Seong, Koh Gwanpyo, et. al. Serum Vitamin D Status and Its Relationship to MetabolicParameters in Patients with Type 2 Diabetes Mellitus. Chonnam Medicine Journal . 201;48:108-15.

[38]. Nikooyeh Bahareh, Neyestani R Tirang, Alavi-Majd Hamid, Kalayi Ali, Shariatzadeh Nastaran, Zahedirad Malihe, et al. Vitamin D Deficiency is Associated with the Metabolic Syndrome in Subjects with Type 2 Diabetes. Nutrition and Food Sciences Research. 2014;1: 3-10.

[39]. Nasri Hamid, Behradmanesh Saeed, Maghsoudi Reza Ahmad, Ahmadi Ali, Nasri Parto, Rafieian-Kopaei Mahmoud. Efficacy of supplementary vitamin D on improvement of glycemic parameters in patients with type 2 diabetes mellitus; a randomized double blind clinical trial. Journal of Renal Injury Prevention. 2014;3(1): 31-4.

[40]. Hummel D., Aggarwal A., Borka K., Bajna E., Kállay E., Horváth H.C. The vitamin D system is deregulated in pancreatic diseases. The Journal of Steroid Biochemistry and Molecular Biology. 2014;144 (B): 402-9.

[41]. Maestro B., Davila N., Carranza M.C., Calle C. Identification of a Vitamin $D$ response element in the human insulin receptor gene promoter. J. Steroid Biochem. Mol. Biol. 2003;84: 223-30.

[42]. Wolden-Kirk H., Overbergh L., Christesen H.T., Brusgaard K., Mathieu C. Vitamin D and diabetes: Its importance for beta cell and immune function. Mol. Cell. Endocrinol. 2011;347:106-120.

[43]. Lee N.K., Sowa H., Hinoi E., Ferron M., Ahn J.D., Confavreux $\mathrm{C}$., et al. Endocrine regulation of energy metabolism by the skeleton. Cell. 2007;(130):45669.

[44]. Lim SK, Kung AW, Sompongse S, Soontrapa S, Tsai KS. Vitamin D inadequacy in postmenopausal women in Eastern Asia. Curr Med Res Opin. 2008;24:99106.

[45]. Van Schoor NM, Lips P. Worldwide vitamin D status. Best Pract Res Clin Endocrinol Metab. 2011;25:67180.

[46]. Lee Byung-Kook, Park Sunmin, Kim Yangho. Age- and gender-specific associations between low serum 25hydroxyvitamin $D$ level and type 2 diabetes in the Korean general population: analysis of 2008-2009 Korean National Health and Nutrition Examination Survey data. Asian Pac Journal Clinical Nutrition .2012; 21(4):536-46.

How to cite this article: Manasa Mekkadath Vijayan, Shivakrishna Gouroju . VITAMIN D2 LEVELS IN TYPE-2 DIABETES MELLITUS PATIENTS IN ANDAMAN AND NICOBAR ISLANDS . Int J Intg Med Sci 2018;5(4):619-624. DOI: 10.16965/ijims.2018.109 